\title{
Adsorption of Lead with Silica Gel Modified with Polyamidoamine Dendrimer and Thiomalic Acid
}

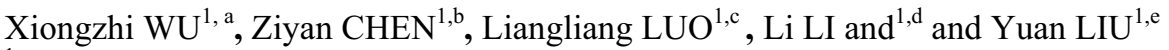 \\ ${ }^{1}$ Department of Chemistry and Biological Engineering, Guilin University of Technology, \\ Guilin 541004, China \\ a2004046@glut.edu.cn ${ }^{1},{ }^{b} 935614725 @ q q . c o m,{ }^{c} 380664562 @ q q . c o m,{ }^{d} 1$ lili19880412@qq.com, \\ e1823805134@qq.com
}

\begin{abstract}
New adsorbents PAMAM-n.0TMSG $(\mathrm{n}=1,2,3,4)$ with thiomalic acid as functional group has been prepared based on polyamidoamine dendrimer modified silica gel and characterized with FTIR, SEM and TG. Microcolumn enrichment and measurement of $\mathrm{Pb}^{2+}$ with graphite furnace atomic absorption spectroscopy (GFAAS) was investigated with PAMAM-n.0TMSG $(\mathrm{n}=1,2,3,4)$ as adsorbent. The adsorption conditions were optimized. The increase of grafted generation of PAMAM-n.0TMSG could effectively improved the adsorption performance of adsorbents. The adsorption capacity of adsorbents was $14.42,16.19,20.79$ and $25.32 \mathrm{mg} \mathrm{g}^{-1}$ respectively, With PAMAM-4.0TMSG as adsorbent, microcolumn enrichment and measurement of $\mathrm{Pb}^{2+}$ with GFAAS was proposed. The relative standard deviation (R.S.D.) was $1.4 \%(\mathrm{n}=11)$ for $0.2 \mu \mathrm{g} \mathrm{mL}^{-1}$ of $\mathrm{Pb}^{2+}$. The limit of detection (LOD) of $2.9 \mathrm{ng} \mathrm{mL}^{-1}$ was achieved. The proposed column enrichment method was applied for detection of $\mathrm{Pb}^{2+}$ in tap water and sea water samples successfully.
\end{abstract}

\section{Introduction}

Because of the low concentration of lead and interference from co-existing substances in environmental sample, Solid-phase extraction (SPE) was often used to preconcentrate and separate trace metals from matrices [1-3] with macroporous adsorption materials such as such as silica-gel [4], chelating resin [5] and organic-inorganic hybrid materials [6,7]. Dendrimer-like polyamidoamine (PAMAM) has attracted considerable attention in metal ions adsorption due to its end amine and ester groups [8-11]. Considering that if silica-gel could be modified with dendrimer-like PAMAM and functional group for adsorption could be linked to the generous peripheral amine group of PAMAM, it would be possible to improve the adsorption capacity of silica-gel and selectivity.

In present work, silica-gel adsorbents PAMAM-n.0TMSG $(n=1,2,3,4)$ with dendrimer-like PAMAM and thiomalic acid as functional groups have been prepared and characterized with FTIR, SEM, and TG, then micro-column adsorption of $\mathrm{Pb}^{2+}$ was investigated. The experiments results showed that modification of PAMAM and thiomalic

* Corresponding author: 2004046@glut.edu.cn 
acid could effectively improve the adsorption/desorption properties of adsorbent. With PAMAM-4.0 TMSG as adsorbent, GFAAS method for analysis of $\mathrm{Pb}^{2+}$ combined with micro-column enrichment was proposed and applied to analysis of $\mathrm{Pb}^{2+}$ of water samples.

\section{Experimental}

\subsection{Apparatus and Reagents}

Peristaltic pump (BT01S-YZ1515) of Yi Kang Xin Da Technology Co., Ltd (China) and a self made micro-column $(7 \mathrm{~cm} \times 0.5 \mathrm{~mm}$ i.d. $)$ were used. PTFE tubing $(0.8 \mathrm{~mm}$ i.d. $)$ was used for connections. Atomic absorption spectrometer (TAS-990) of Beijing Purkinje General Instrument Co., Ltd. (China) was employed to detection of $\mathrm{Pb}^{2+}$.

Silica gel ( 60-100 meshes, surface area 300-600 $\mathrm{m}^{2} \mathrm{~g}^{-1}$ ) was bought from Qingdao Shuoyuan Chemical Co. Ltd., China. $\gamma$-Aminopropyltriethoxysilane (Beijing Shenda Fine Chemical Co. Ltd., China) was purified by distillation at $123^{\circ} \mathrm{C}$ under $10 \mathrm{~mm} \mathrm{Hg}$. All of the other reagents were analytical reagent grade. 1-(3-Dimethylaminopropyl)-3-ethylcarbodiimide hydrochloride(EDC), thiomalic acid and N-Hydroxysuccinimide(NHS) were all bought from Aladdin Chemistry Co.Ltd. Stock solution of $\mathrm{Pb}^{2+}\left(1000 \mathrm{mg} \mathrm{L}^{-1}\right)$ was prepared by dissolving appropriate amounts of analytical pure $\mathrm{Pb}\left(\mathrm{NO}_{3}\right)_{2}$ in $\mathrm{pH}=2 \mathrm{HNO}_{3}$ solution. Standard solutions of $\mathrm{Pb}^{2+}$ were prepared by dilution of the stock solution just before use. Distilled water was used throughout.

\subsection{Preparation of PAMAM-n.OTMSG}

Pretreatment of silica-gel and synthesis of aminopropyl silica-gel (APSG) and dendrimer-like PAMAM modified silica-gel PAMAM-n.0SG $(n=1,2,3,4)$ were followed as described previously [10]. PAMAM-n.0TMSG $(\mathrm{n}=1,2,3,4)$ was prepared as below. $4.505 \mathrm{~g}$ thiomalic acid,1.036 g NHSand 8.626g EDC were dissolved in $250 \mathrm{~mL}$ flask with appropriate amounts of N,N-Dimethylformamide (DMF).Then $10 \mathrm{~g}$ PAMAM-n.0SG(n=1,2,3,4) was added into the flask. In room temperature the mixture was stirred for $24 \mathrm{~h}$ to obtain solid products PAMAM-n.0TMSG(n=1,2,3,4).

PAMAM-n.0TMSG $(\mathrm{n}=1,2,3,4)$ were washed with DMF at least for 3 times, then wahed with ethanol at least for 3 times. PAMAM-n.0TMSG $(n=1,2,3,4)$ were dried at $70{ }^{\circ} \mathrm{C}$. The ideal synthetic route of PAMAM-n.0TMSG $(n=1,2,3,4)$ was illustrated in Scheme 1. 

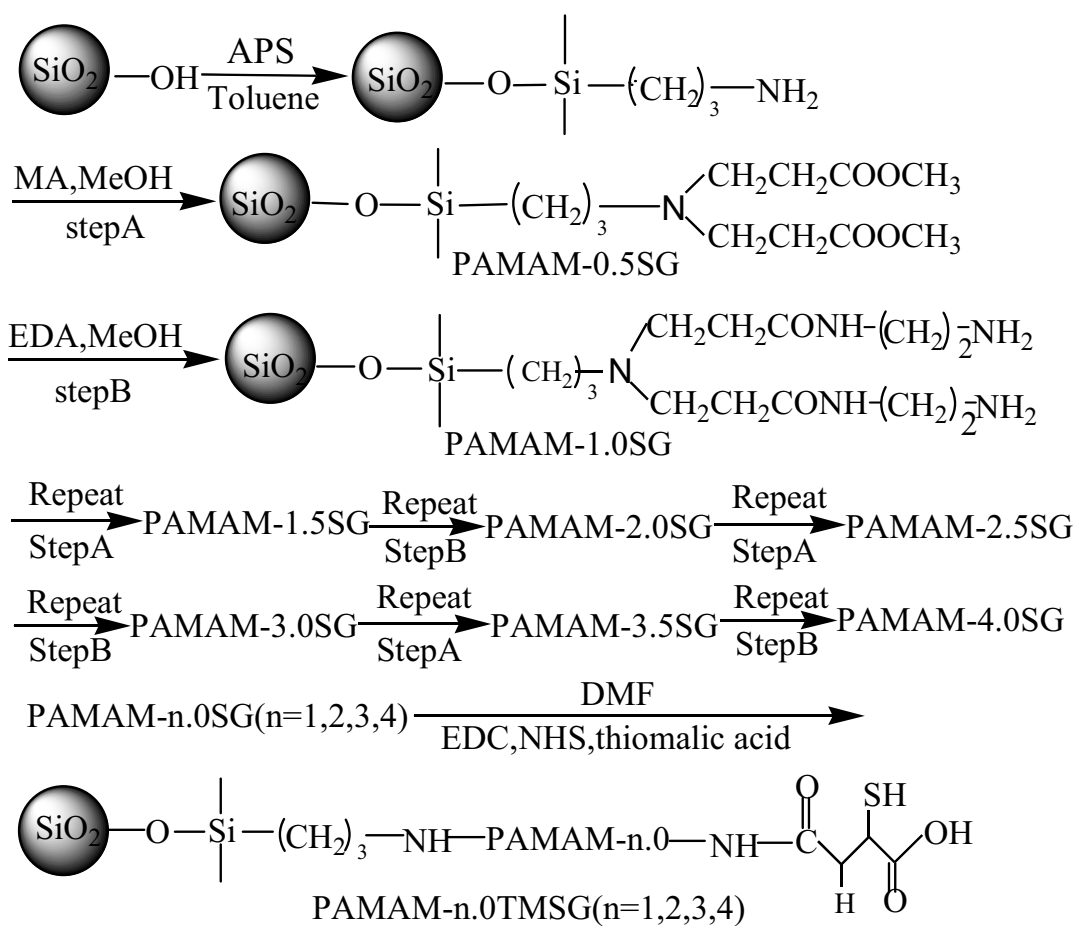

Scheme 1 The ideal synthetic route to PAMAM-n.0TMSG $(n=1,2,3,4)$

\subsection{Enrichment Procedure}

One end of the micro-column was packed with polypropylene fiber, PAMAM-n.0TMSG $(\mathrm{n}=1,2,3,4)$ was packed in micro-column, then the other end of the micro-column was packed with polypropylene fiber, two ends were connected with silicone tubing. In Step 1, the blank solution (its $\mathrm{pH}$ is the same as $\mathrm{Pb}^{2+}$ solution) was pumped through micro-column. In Step 2, the $\mathrm{Pb}^{2+}$ solution was pumped through micro-column and was collected for determination of $\mathrm{Pb}^{2+}$. In Step 3, the blank solution was pumped through micro-column. In Step 4, the eluent solution was pumped through micro-column in the reverse direction and was collected for determination of $\mathrm{Pb}^{2+} . \mathrm{Pb}^{2+}$ concentration was determined with GFAAS. $\mathrm{Pb}^{2+}$ adsorption percentage (A) and desorption percentage ( R) were calculated according to (1) and (2).

$$
\begin{aligned}
& A=\frac{C_{0} V_{0}-C_{1} V_{1}}{C_{0} V_{0}} \times 100 \% \\
& R=\frac{C_{2} V_{2}}{C_{0} V_{0}-C_{1} V_{1}} \times 100 \%
\end{aligned}
$$

While $\mathrm{C}_{0}$ and $\mathrm{C}_{1}\left(\mu \mathrm{g} \mathrm{mL^{-1 }}\right)$ are concentration of $\mathrm{Pb}^{2+}$ in the sample solution before and after adsorption, $\mathrm{C}_{2}\left(\mu \mathrm{g} \mathrm{mL} \mathrm{m}^{-1}\right)$ is concentration of $\mathrm{Pb}^{2+}$ in elutant through micro-column in step 4; $V_{0}$ and $V_{1}(\mathrm{~mL})$ are the volume of sample solution before and after adsorption, $\mathrm{V}_{2}(\mathrm{~mL})$ is elutant volume. 


\section{Results and Discussion}

\subsection{Characterization of Adsorbent}

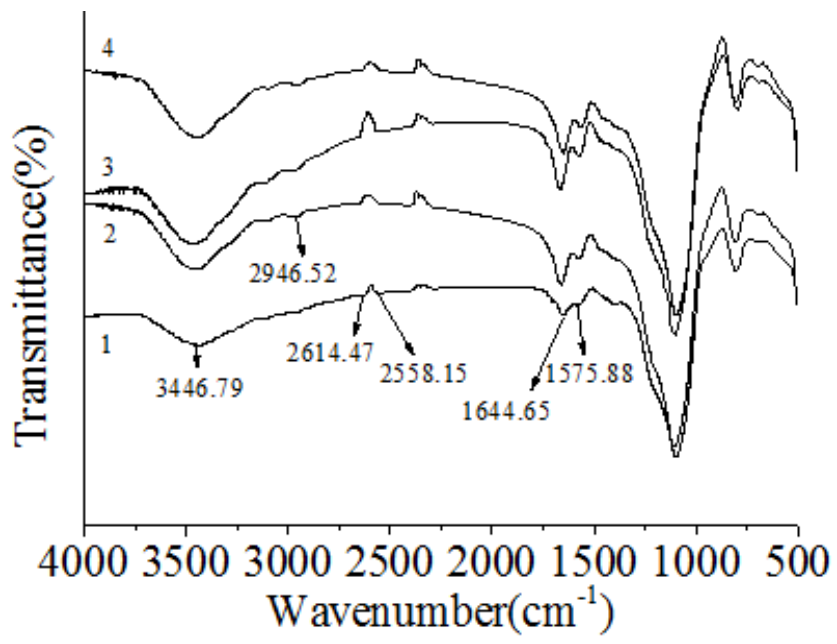

Fig.1 FTIR spectra of PAMAM-n.0TMSG $(n=1,2,3,4)$

The Fourier transmission infra-red (FTIR) spectra of PAMAM-n.0TMSG $(n=1,2,3,4)$ are shown in Fig.1. The absorption at $3346 \mathrm{~cm}^{-1}$ is characteristic of $-\mathrm{NH}_{2}$ and $-\mathrm{OH}$ stretching vibration and the absorption at $2946 \mathrm{~cm}^{-1}$ is characteristic of $-\mathrm{CH}_{2}-$ stretching vibration. The absorption at $1644 \mathrm{~cm}^{-1}$ and $1575 \mathrm{~cm}^{-1}$ is characteristic of $\mathrm{C}=\mathrm{O}$ stretching vibration in amide groups and N-H scissorvibration respectively. The absorption at $2614 \mathrm{~cm}^{-1}$ and $2558 \mathrm{~cm}^{-1}$ is characteristic of -SH vibration. The appearance of these characteristic absorptions suggested that PAMAM and thiomalic acid were successfully introduced onto the surface of silica-gel.

Fig. 2 presents SEM images (magnified fifty thousand times) of PAMAM-n.0TMSG $(n=1,2,3,4)$. On the rough surface of APSG there are many pores with kinds of diameter. As the increase of PAMAM grafting generation, more surface was covered by PAMAM, indicating that dendrimer-like PAMAM had been successfully grafted onto the surface of silica gel.

TG analysis was applied to evaluate the grafting effectiveness of PAMAM onto the surface of silica gel. Under $\mathrm{N}_{2}$ atmosphere, temperature range was from 30 to $600{ }^{\circ} \mathrm{C}$ with heating rate of $5{ }^{\circ} \mathrm{C} \mathrm{min}{ }^{-1}$ during TG analysis. When the temperature reached $100{ }^{\circ} \mathrm{C}$, the weight loss were about 2.09-8.23\%, which represented the evaporation of water adsorbed on silica-gel. When the temperature reached $600{ }^{\circ} \mathrm{C}$, the total weight loss of APSG, PAMAM-n.0TMSG(n=1,2,3,4) were 11.69, 22.42, 26.46, 27.43 and 33.08\% respectively, suggesting that grafting percentage of PAMAM increased with the increase of grafting generation number of PAMAM.

\subsection{Effect of $\mathrm{pH}$}

In the range from $2.0-9.0$, adsorption rate of $\mathrm{Pb}^{2+}$ reached more than $95 \%$ when $\mathrm{pH}$ is in the range of $5-8$. The solution of $\mathrm{pH}=5.0$ was selected as the sample medium. 


\subsection{Effect of Eluent concentration}

In the range of $0.05-4.0 \mathrm{~mol} \mathrm{~L}^{-1}, \mathrm{~Pb}^{2+}$ could be eluted by $1.0 \mathrm{~mol} \mathrm{~L}^{-1} \mathrm{HCl}$ solution with PAMAM- n.0TMSG $(\mathrm{n}=1,2)$ as adsorbent and by $0.1 \mathrm{~mol} \mathrm{~L}^{-1} \mathrm{HCl}$ solution with PAMAM-n.0TMSG(n=3,4) as adsorbent. In order to guarantee the elution of $\mathrm{Pb}^{2+}, 1.0,1.0$, 0.1 and $0.1 \mathrm{~mol} \mathrm{~L}^{-1} \mathrm{HCl}$ solution was used as eluent respectively in further experiments.

\subsection{Effect of Flow Rate}

In the sample solution flow rate range of $0.6-6.0 \mathrm{ml} \mathrm{min}{ }^{-1}$, adsorption rate of $\mathrm{Pb}^{2+}$ reached more than $95 \%$. So $4.2 \mathrm{~mL} \mathrm{~min}^{-1}$ was used as the sample solution flow rate.

In the eluent solution flow rate range of $0.6-6.0 \mathrm{ml} \mathrm{min}^{-1}$, recovery of $\mathrm{Pb}^{2+}$ reached more than $95 \%$ with a flow rate of $3.0 \mathrm{~mL} \mathrm{~min}^{-1}$ and with PAMAM-1.0TMSG or PAMAM-2.0TMSG as assorbent. Recovery of $\mathrm{Pb}^{2+}$ reached more than $95 \%$ with a flow rate of 3.6-4.8 $\mathrm{mL} \mathrm{min}^{-1}$ and with PAMAM-3.0TMSG or PAMAM-4.0TMSG as assorbent.In order to guarantee the elution of $\mathrm{Pb}^{2+}, 3.0,3.0,4.2$ and $4.2 \mathrm{~mL} \mathrm{~min}^{-1}$ was used as eluent solution flow rate respectively in further experiments.

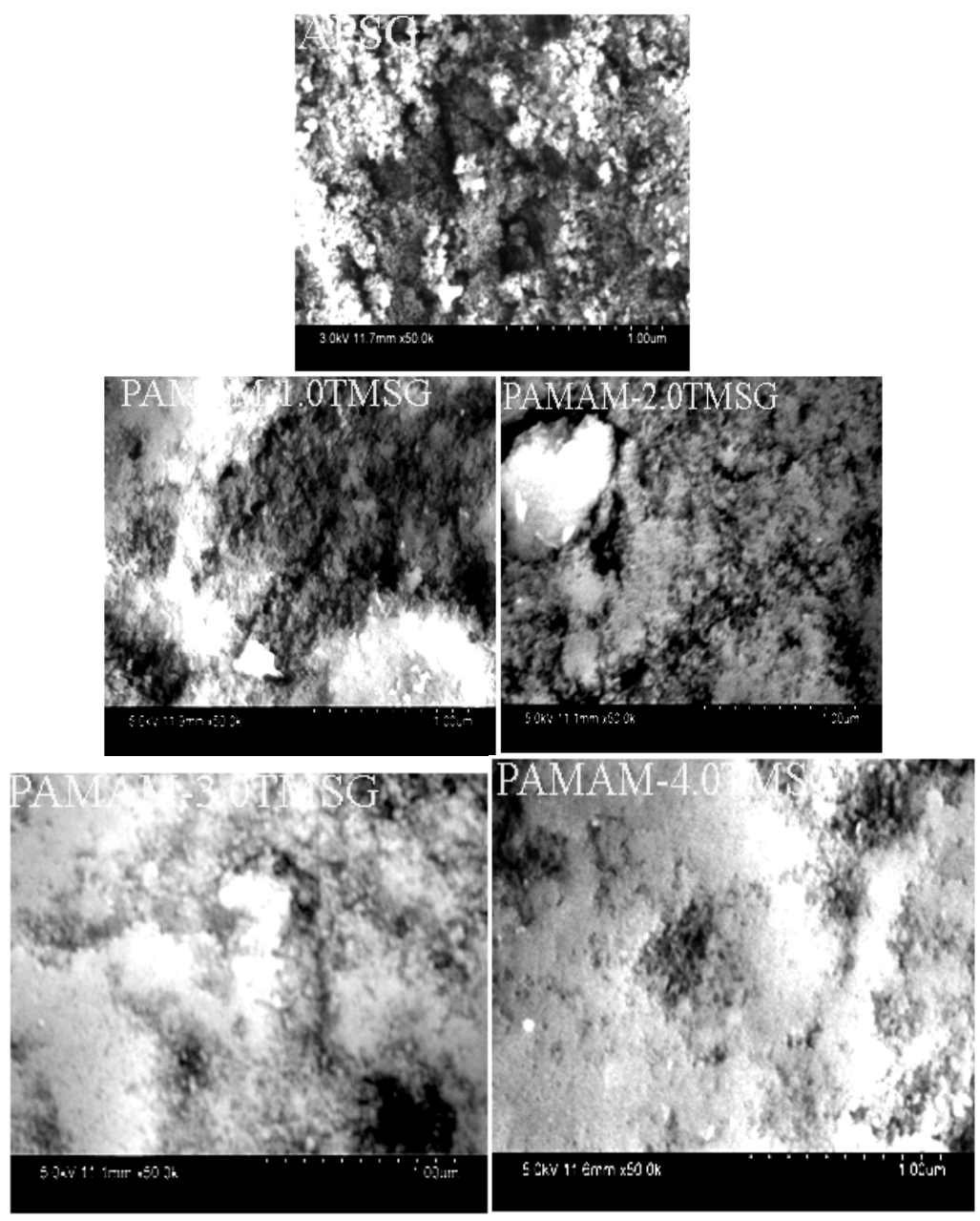

Fig.2 The SEM images of APSG and PAMAM-n.0TMSG $(n=1,2,3,4)$ 


\subsection{Effect of Sample and Eluent Solution Volume}

Under the above selected conditions, different volume $(5.0-40.0 \mathrm{ml})$ sample solution of $0.2 \mu \mathrm{g} \mathrm{mL} \mathrm{m}^{-1} \mathrm{~Pb}^{2+}$ was used respectively for sample loading. When sample solution volume was not more than $10.0 \mathrm{ml}$, adsorption rate of $\mathrm{Pb}^{2+}$ were more than $95 \%$. Different volume $(5.0-40.0 \mathrm{ml}) \mathrm{HCl}$ solution was used as eluent, and elution recovery of $\mathrm{Pb}^{2+}$ could reach more than $95 \%$. So $10.0 \mathrm{ml}$ sample solution and $10.0 \mathrm{ml}$ eluent solution were selected in the further experiments.

\subsection{Interference of Co-exiting lons}

The effects of anions and co-existing metal ions were tested when $10 \mathrm{ml}$ sample solution with $0.2 \mu \mathrm{g} \mathrm{mL}^{-1} \mathrm{~Pb}^{2+}$ was determined. More than $5 \mu \mathrm{g} \mathrm{mL}{ }^{-1}$ of co-existing metal ions $\left(\mathrm{Na}^{+}\right.$, $\left.\mathrm{K}^{+}, \mathrm{Ca}^{2+}, \mathrm{Mg}^{2+}, \mathrm{Zn}^{2+}, \mathrm{Al}^{3+}, \mathrm{Mn}^{2+}, \mathrm{Cu}^{2+}, \mathrm{Cr}^{3+}, \mathrm{Co}^{2+}, \mathrm{Cd}^{2+}, \mathrm{Ni}^{2+}, \mathrm{Fe}^{3+}\right)$ and $100 \mu \mathrm{g} \bullet \mathrm{ml}^{-1}$ of anions $\left(\mathrm{PO}_{4}{ }^{3-}, \mathrm{SO}_{4}{ }^{2-}, \mathrm{NO}_{3}{ }^{-}, \mathrm{ClO}_{4}{ }^{-}, \mathrm{Cl}^{-}\right)$(added as sodium salts) did not interfere with the enrichment and determination.

\subsection{Saturated Adsorption Capacity}

Under the above selected conditions, $40.0 \mu \mathrm{g} \mathrm{mL}^{-1} \mathrm{~Pb}^{2+}$ solution $(\mathrm{pH}=5.0)$ passed through micro-column with flow rate of $1.8 \mathrm{~mL} \mathrm{~min}^{-1}$. The saturated adsorption capacity of PAMAM-n.0TMSG $(\mathrm{n}=1,2,3,4)$ for $\mathrm{Pb}^{2+}$ were $14.42,16.19,20.79$ and $25.32 \mathrm{mg} \mathrm{g}^{-1}$, which indicated that the increase of grafting generation of PAMAM was helpful for increase of functional group amount and adsorption capacity of adsorbent.

\subsection{Low Concentration Enrichment}

$\mathrm{Pb}^{2+}$ solutions with $2 \mu \mathrm{g} \quad \mathrm{Pb}^{2+} \quad$ and different volume $(10 \mathrm{~mL}, 100 \mathrm{~mL}, 1000 \mathrm{~mL}, 1500 \mathrm{~mL}, 2000 \mathrm{~mL})$ were respectively enriched according to the procedure and then $\mathrm{Pb}^{2+}$ was eluted with $10.0 \mathrm{ml}$ eluent and determined. $2.0 \mu \mathrm{g} \mathrm{Pb}^{2+}$ in 1000 $\mathrm{mL}$ solution could be quantitatively preconcentrated with PAMAM-1.0SSASG or PAMAM-2.0SSASG and eluted with $10 \mathrm{~mL}$ eluent and a factor of 100 was obtained. The enrichment factor with PAMAM-n0SSASG $(n=1,2,3,4)$ as adsorbents respectively was $100,100,150$ and 200 .

\subsection{Analytical Performances}

The characteristic data for the analytical performance of microcolumn enrichment system with PAMAM-4.0TMSG as adsorbent and GFAAS detction of $\mathrm{Pb}^{2+}$ are investigated. With the proposed method, the relative standard deviation (R.S.D.) was $1.4 \%$ for $0.2 \mu \mathrm{g} \mathrm{mL}^{-1}$ of $\mathrm{Pb}^{2+}$. The limit of detection (LOD) was $2.9 \mathrm{ng} \mathrm{mL}^{-1}$, calculated as the concentration of $\mathrm{Pb}^{2+}$ required to yield a net peak-height absorbance that was equal to three times the standard deviation of the background signal $(3 \sigma)$ of the blank solution. Regression equation (five standards, $\mathrm{n}=5, C$ in $\mu \mathrm{g} \mathrm{mL}^{-1}$ ) was $\mathrm{A}=3.0952 * \mathrm{C}+0.1090$ in $\mathrm{Pb}^{2+}$ concentration range of $0.05-0.3 \mu \mathrm{g} \mathrm{mL}^{-1}$ with a correlation coefficient $\mathrm{R}=0.9990$. 


\subsection{Water Sample Analysis}

TABLE 1 DETERMINATION OF PB $^{2+}$ IN WATER SAMPLES AND ADDITION-RECOVERY TESTS

\begin{tabular}{ccccc}
\hline Sample & $\begin{array}{c}\text { Added } \\
\left(\mu \mathrm{g} \mathrm{mL}^{-1}\right)\end{array}$ & $\begin{array}{c}\text { Found }^{\mathrm{a}} \\
\left(\mu \mathrm{g} \mathrm{mL}^{-1}\right)\end{array}$ & $\begin{array}{c}\text { RSD } \\
(\%)\end{array}$ & $\begin{array}{c}\text { Recovery } \\
(\%)\end{array}$ \\
\hline \multirow{3}{*}{ tap water } & 0 & unfound & 2.0 & -- \\
& 0.005 & 0.0052 & 1.6 & 104.0 \\
& 0.010 & 0.0099 & 2.8 & 99.0 \\
sea water & 0.020 & 0.0201 & 4.5 & 100.5 \\
& 0 & 0.0031 & 1.7 & \\
& 0.005 & 0.0083 & 1.3 & 104.0 \\
& 0.010 & 0.00134 & 0.8 & 103.0 \\
& 0.020 & 0.00230 & 2.6 & 99.5 \\
\hline
\end{tabular}

${ }^{a}$ Mean $(\mathrm{n}=6)$

The proposed column enrichment method was applied for the preconcentration and determination of $\mathrm{Pb}^{2+}$ in tap water and sea water samples $(100 \mathrm{~mL})$. The standard addition method was applied for evaluation of the method in analysis of water samples. The analytical results are given in Table 1. As it can be seen, the recoveries of $\mathrm{Pb}^{2+}$ are in the range of 98.0-105.0\% with R.S.D not more than 5.0\%. The results indicate that the proposed method is reliable.

\section{Summary}

PAMAM-n.0TMSG $(n=1,2,3,4)$ adsorbents withPAMAM and thiomalic acid as functional groups have been synthesized and characterized with FTIR,SEM andTG, then enrichment conditions for $\mathrm{Pb}^{2+}$ was investigated. PAMAM-n.0TMSG showed good adsorption capability. The proposed column enrichment-GFAAS method was successfully applied for detection of $\mathrm{Pb}^{2+}$ in tap water and sea water samples.

\section{Acknowledgments}

This work was financially supported by the National Natural Science Foundation of China (No. 51262005), Guangxi Colleges and Universities Key Laboratory of Food Safety and Detection, and the project of high level innovation team and outstanding scholar in Guangxi colleges and universities(No.49 2014).

\section{References}

1. T. Madrakian, M.A. Zolfigol, M. Solgi, Solid-phase extraction method for preconcentration of trace amounts of some metal ions in environmental samples using silica gel modified by 2,4,6-trimorpholino-1,3,5-triazin, J. Hazard. Mater. 160 (2008) 468-472.

2. M. L. Chen, Y. Sun, C. B. Huo, C. Liu, J. H. Wang, Akaganeite decorated graphene oxide composite for arsenic adsorption/removal and its proconcentration at ultra-trace level, Chemosphere 130 (2015) 52-58.

3. Y. Wang, S. Gao, X. Zang, J. Li, J. Ma, Graphene-based solid-phase extraction combined with flame atomic absorption spectrometry for a sensitive determination of trace amounts of lead in environmental water and vegetable samples, Anal. Chim. Acta 716 (2012) 112-118. 
4. K. Johari, N. Saman, H. Mat, Adsorption enhancement of elemental mercury onto sulphur-functionalized silica gel adsorbents, Environ. Technol. 35 (2014) 629-636.

5. Y. Zhai, Y. Liu, X. Chang, S. Chen, X. Huang, Selective solid-phase extraction of trace cadmium(II) with an ionic imprinted polymer prepared from a dual-ligand monomer, Anal. Chim. Acta 593 (2007) 123-128.

6. H.T. Fan, X.T. Sun, W.X. Li, Sol-gel derived ion-imprinted silica-supported organic-inorganic hybrid sorbent for selective removal of lead(II) from aqueous solution, J. Sol-Gel Sci. Technol. 72 (2014) 144-155.

7. M. Rashid, F. Khan, Lutfullah, Removal of $\mathrm{Pb}(\mathrm{II})$ ions from aqueous solutions using hybrid organic-inorganic composite material: $\mathrm{Zr}(\mathrm{IV})$ iodosulphosalicylate, J. Water. Process Eng. 3 (2014) 53-61.

8. R. Qu, Y. Niu, C. Sun, C. Ji, C. Wang, G. Cheng, Syntheses, characterization, and adsorption properties for metal ions of silica-gel functionalized by ester- and amino-terminated dendrimer-like polyamidoamine polymer, Microporous Mesoporous Mater. 97 (2006) 58-65.

9. Y. Niu, R. Qu, C. Sun, C. Wang, H. Chen, C. Ji, Y. Zhang, X. Shao, F. Bu, Adsorption of $\mathrm{Pb}$ (II) from aqueous solution by silica-gel supported hyperbranched polyamidoamine dendrimers, J. Hazard. Mater. 244-245 (2013) 276-286.

10. X. Z. Wu, P. Liu, Q.S. Pu, Q.Y. Sun, Z. X. Su, Preparation of dendrimer-like polyamidoamine immobilized silica gel and its application to online preconcentration and separation palladium prior to FAAS determination, Talanta 62 (2004) 918-923.

11. Y. Niu, R. Qu, H. Chen, L. Mu, X. Liu, T. Wang, Y. Zhang, C. Sun, Synthesis of silica gel supported salicylaldehyde modified PAMAM dendrimers for the effective removal of $\mathrm{Hg}$ (II) from aqueous solution, J. Hazard. Mater. 278 (2014) 267-278. 